\title{
A cluster-randomised controlled trial of a school-based fruit and vegetable intervention: Project Tomato
}

\author{
Charlotte EL Evans ${ }^{1}$, Joan K Ransley ${ }^{1}$, Meaghan S Christian ${ }^{1}$, Darren C Greenwood ${ }^{2}$, \\ James D Thomas ${ }^{1}$ and Janet E Cade ${ }^{1, *}$ \\ ${ }^{1}$ Nutritional Epidemiology Group, School of Food Science and Nutrition, University of Leeds, Leeds, Leeds LS2 \\ 9JT, UK: ${ }^{2}$ Centre for Epidemiology and Biostatistics, University of Leeds, University of Leeds, Leeds, UK
}

Submitted 12 May 2011: Final revision received 31 0ctober 2012: Accepted 1 November 2012: First published online 14 December 2012

\begin{abstract}
Objective: The present study aimed to determine whether a multi-component school-based intervention can maintain children's fruit and vegetable intake post eligibility for free school fruit and vegetables.

Design: A random sample of fifty-four English primary schools was randomised to receive the 10-month intervention Project Tomato, a multi-component theorybased intervention, or the control. Each group consisted of twenty-seven schools. Setting: Children's intake of fruit and vegetables is below recommendations. The English School Fruit and Vegetable Scheme has a short-term impact on intake while children are eligible for the scheme.

Subjects: Dietary measurements were collected from 658 Year 2 pupils aged 7-8 years at baseline and at follow-up 20 months later.

Results: Following an intention to treat analysis, the intervention as delivered compared with the control had no impact on the intake of fruit and vegetables $(2 \mathrm{~g} / \mathrm{d}, 95 \% \mathrm{CI}-23,26 \mathrm{~g} / \mathrm{d})$ or on the number of portions of fruit $(0.0$ portions, $95 \% \mathrm{CI}-0 \cdot 3,0 \cdot 3)$ or vegetables $(0 \cdot 0$ portions, $95 \% \mathrm{CI}-0 \cdot 2,0 \cdot 3)$ consumed daily by children. Intake of fruit and vegetables at school and home dropped by $\sim 100 \mathrm{~g} / \mathrm{d}$ and $50 \mathrm{~g} / \mathrm{d}$, respectively, between baseline and follow-up in both the intervention and control groups.

Conclusions: Implementation of the intervention was low, with associated lack of impact on fruit and vegetable consumption in children. Alternatives to the delivery of an intervention by teachers and parents are needed to improve the dietary intake of primary-school children.
\end{abstract}

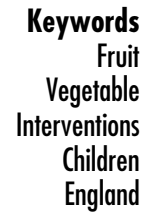

A diet rich in fruit and vegetables may decrease the risk of developing chronic diseases such as CVD, stroke, obesity and several forms of cancer in adult life ${ }^{(1,2)}$. For some cancer sites, the risk of developing cancer doubles with adult diets in the lowest quartile of intake of fruit and vegetables compared with the upper quartile of intake ${ }^{(3)}$. Good dietary habits developed in childhood may persist and lead to improved diet and health in adulthood ${ }^{(4,5)}$.

The recommended intake of fruit and vegetables for adults and children in the UK and other Western countries is $400 \mathrm{~g} / \mathrm{d}$. This is equivalent to five $80 \mathrm{~g}$ portions of fruit and vegetables daily ${ }^{(2)}$. In other countries recommendations are higher. In Australia the 'Go for 2 \& 5' campaign recommends a daily intake of at least two pieces of fruit and five vegetables ${ }^{(6)}$. Denmark recommends $600 \mathrm{~g} / \mathrm{d}^{(7,8)}$. Surveys indicate that children living in Western countries are consuming considerably less than these recommendations $^{(9-12)}$. A UK survey reported children's intake to be 2.5 portions of fruit and vegetables daily. In Australia and the USA consumption is slightly higher ${ }^{(11,12)}$.
The School Fruit and Vegetable Scheme (SFVS) was launched in 2004 as part of the UK's 5-A-Day strategy to improve children's consumption of fruit and vegetables ${ }^{(13)}$. This scheme provides a free piece of fruit or vegetable each school day to children from the age of 4 years, for the first three years of school ${ }^{(14)}$. The scheme distributes $\sim 440$ million pieces of fruit and vegetables each year to over two million children in 18000 schools across England ${ }^{(15)}$.

Studies evaluating the SFVS suggest that it increases children's fruit and vegetable intake in the short term, while children receive the free fruit or vegetable, but this falls when children are no longer eligible for the scheme. There appears to be no long-term impact of this scheme on fruit and vegetable intake of children ${ }^{(9,16,17)}$.

A number of school-based multi-component intervention trials to improve fruit and vegetable intake in children have been carried out which include elements to improve the school curriculum as well as providing home-based projects $^{(18-25)}$. The majority of these studies are US-based 
and also include components to improve the school environment. Two trials reported in the literature are based in the UK; one in Dundee ${ }^{(24)}$ and one in Leeds ${ }^{(25)}$. The former included improvements to the curriculum and communications with parents and successfully improved fruit and vegetable consumption, while the latter focused on improving the curriculum and the school environment and reported little impact on fruit and vegetable intake.

There is a need for a school-based programme to maintain the increased intake of fruit following children's participation in the SFVS during the first three years of school. Project Tomato is a flexible, multi-component, theory-based intervention designed to do just this. The intervention is designed for children in school Years 3 and 4 (aged 7-9 years) who no longer receive free fruit and vegetables at school. It contains components which aim to both improve the school curriculum and engage parents and children at home using a variety of homebased projects.

The present study reports results from Project Tomato, the first-cluster randomised controlled trial in the UK to study the maintenance of fruit and vegetable intake post SFVS in a large number of schools across England.

\section{Methods}

\section{Sampling metbod and study design}

In 2006, a nationally representative sample of 130 primary schools across England formed a cross-sectional survey of children's fruit and vegetable intake. Schools were randomly sampled from the National Foundation of Educational Research (NFER) database of all schools. Schools were excluded if they had fewer than fifteen pupils per class, did not have pupils in Years 2-4, were independent or special schools, or were schools that had previously participated in SFVS projects. All schools were stratified on the following background criteria to ensure the sample was representative of English schools: Local Education Authority type (e.g. rural/metropolitan); school type (e.g. infant, primary); Key Stage One academic attainment (percentage of pupils achieving level two on Standard Assessment Tasks); percentage of pupils eligible for free school meals; percentage of pupils defined as having special educational needs; and percentage of pupils with English as an additional language. From the sample of 130 schools assessed at baseline, a subset of fifty-four schools was selected using a random allocation sequence generated by a computerised random number generator and recruited to the Project Tomato cluster-randomised controlled trial.

Eligible schools were sent a letter, additional information and a consent form inviting them to take part in the study. Parents received a letter with information about the study two weeks prior to the data collection date. The letter contained a self-completed reply slip providing the parents or guardians the opportunity for their child not to take part in the study (opt-out consent). Parents who did not wish their child to participate completed the reply slip, which was then returned to the school. Ethics approval was obtained through the University of Leeds Central Research Ethics Committee.

Fifty-four schools with 1031 children aged 7-8 years (Year 2) were randomised by school to either the intervention or control group. Block randomisation within strata was used (blocks of two) stratifying on ethnicity (percentage of pupils non-white British) and deprivation (percentage of pupils eligible for free school meals), both split at the median. Baseline data were collected between February and March 2007, and follow-up data were collected between September and October 2008 when these children were in Year 4.

\section{The intervention}

The intervention, Project Tomato, was designed using a framework of health maintenance behaviour which included the following components: familiarising children with fruit and vegetables through activities such as gardening and cooking; repeated exposure to eating fruit and vegetables through tasting sessions and school meals; engaging children in activities relating to these foods through science experiments and growing; encouraging adult and peer modelling of desirable behaviours such as eating fruit; and ensuring that the environment of the school promotes the eating of fruit and vegetables ${ }^{(15,26,27)}$. This approach was summarised by the acronym FRAME (Familiarisation, Repetition, Activities, Modelling and Environment).

The duration of the intervention was 10 months from July 2007 to April 2008. All schools received core intervention materials and activities consisting of a manual, twelve lesson plans, two newsletters, advice for parents, three take-home activity bags, and instructions for setting up a committee. In addition, schools received customised modules of materials and activities depending on their baseline level of activity in a number of key areas relating to promoting fruit and vegetable consumption, such as a cooking club or gardening club. For example, if a school did not have a gardening club, the head teacher was asked if they would like information to help them set up a club for Year 2 children in their school. The intervention participants - teachers, parents and children - were asked to complete questionnaires on the intervention materials to identify aspects relating to implementation and appreciation of the intervention. Baseline level of school activity to promote fruit and vegetable consumption was assessed by a questionnaire completed by a Year 3 teacher.

The control schools received a '5-A-DAY' booklet and healthy eating leaflets to distribute to parents of Year 2 pupils $^{(13)}$.

\section{Dietary assessment}

Dietary intake was assessed using a validated $24 \mathrm{~h}$ dietary assessment tool, the Child and Diet Evaluation Tool 
(CADET) diary ${ }^{(28)}$. The CADET diary comprises of a list of 105 separate food and drink types, divided into fifteen categories. The categories of foods are: (i) cereal (five items); (ii) sandwich/bread/cake/biscuit (ten items); (iii) spreads/sauces/soup (seven items); (iv) cheese/egg (six items); (v) chicken/turkey (three items); (vi) meat other (nine items); (vii) fish (five items); (viii) vegetarian (three items); (ix) pizza/pasta/rice (eight items); (x) desserts/ puddings (three items); (xi) sweets/crisps (four items); (xii) vegetables and beans (eighteen items); (xiii) potato (two items); (xiv) fruit (thirteen items); and (xv) drinks (nine items). Each item in the diary has seven tick boxes related to different meal time options: 'morning break', 'lunch time', 'afternoon break', 'before tea (after school)', 'evening meal/tea', 'after tea/during night' and 'breakfast/ before school'. The diary is completed by a parent or guardian at home and by trained field workers at school; they are required to tick each item consumed by the child, under the appropriate meal time heading, within the $24 \mathrm{~h}$ period. For this analysis the NFER field workers completed the CADET diary during school hours. Parents were asked to record what their child ate in the evening and before school the next day. Gender- and age-specific portion sizes were applied to the data based on UK national survey results ${ }^{(10)}$.

\section{Statistical analysis}

Twenty schools were required with 500 children per group to have $90 \%$ power to detect a 0.5 portion difference in fruit or vegetable intake. Further details on the sampling methodology are reported elsewhere ${ }^{(15)}$.

Children who had no ticks in their diary for the home time periods were excluded from the analysis. Children were also excluded if they had more than forty ticks on their CADET diary as this indicated that they were using the CADET diary incorrectly.

To assess the impact of the intervention on changes in children's fruit and vegetable intake, an intention to treat analysis was undertaken. Multilevel regression modelling was conducted using MLwiN ${ }^{(29)}$. This model takes into consideration the hierarchical structure of the data caused by cluster randomisation: school level and child level ${ }^{(15)}$. This type of analysis is appropriate as children within the same school are likely to be more similar to each other than to others in a different school in terms of fruit and vegetable intake. A random intercepts model was used with total weight of fruit and vegetables, weight of fruit only and weight of vegetables only used as the main outcomes. Weights were also converted to portions. To determine the intervention effects, baseline levels and age were included in the model as covariates (fixed effects), together with intervention status and gender as dummy variables (fixed effects). Results for school and home separately are reported as medians with interquartile range due to the data not being normally distributed. Vitamin $\mathrm{C}$ and vitamin A were log transformed as they are not normally distributed based on previous research ${ }^{(10)}$.

\section{Results}

Fifty-four schools were randomised into the trial. Fifty schools (twenty-six control and twenty-four intervention) completed the trial. Trial materials were allocated to 1080 children and 1031 received the materials: fourteen children were opted out by their parents; thirty-one were absent on the baseline collection day; and four children had left the school before data collection. CADET diaries were returned from 781 ( $76 \%$ of those receiving materials) children who completed it at both baseline and follow-up. Data from 658 children (64\% of those receiving materials: 347 control and 311 intervention) were used in the analysis. Poor completion of CADET resulted in 123 children being excluded from the analysis. Reasons for the loss of children randomised to the trial included: absence on the day of the survey; a move from the school between baseline and follow-up; and withdrawal of schools due to entering special measures (see Figs 1 and 2).

Table 1 shows baseline intakes of fruit, vegetables and key nutrients in the control and intervention groups. Intakes of food and key nutrients and energy were closely matched at baseline across intervention and control groups. The combined mean daily fruit and vegetable intake was similar in both groups (control: $305 \mathrm{~g}, 95 \%$ CI 286, 324g; intervention: $309 \mathrm{~g}, 95 \%$ CI $287,332 \mathrm{~g}$ ). Comparison of the characteristics of children in the control and intervention group at baseline is shown in Table 1. There were also negligible differences in age, sex, height, weight and deprivation; however, there were slightly more children from different ethnic groups in the control compared with the intervention group $(21 \cdot 7 \%, 95 \%$ CI $14 \cdot 2,33 \cdot 2 \%$ v. $14 \cdot 4 \%, 95 \%$ CI $8 \cdot 3$, $23 \cdot 1 \%$, respectively). Slightly more children were eligible for free school meals in the control group compared with the intervention group.

Project Tomato was evaluated by comparing fruit and vegetable intake between children in the intervention group and children in the control group at follow-up. Both groups were similar in terms of fruit and vegetable intake (mean difference: $2 \mathrm{~g} / \mathrm{d}, 95 \% \mathrm{CI}-23,26 \mathrm{~g} / \mathrm{d}$ ). This difference was not statistically significant. There was no effect of the intervention as delivered on the number of portions of fruit $(0.0$ portions, $95 \%$ CI $-0.3,0.3)$ or vegetables $(0 \cdot 0$ portions, $95 \% \mathrm{CI}-0 \cdot 2,0 \cdot 3)$ consumed daily. Fruit intake was slightly higher than vegetable intake in both groups. There were no differences between the two groups of children in terms of intakes of key nutrients (Table 2). Intake of fruit and vegetables combined fell by $\sim 50 \mathrm{~g} / \mathrm{d}$ between baseline and followup in both groups. 


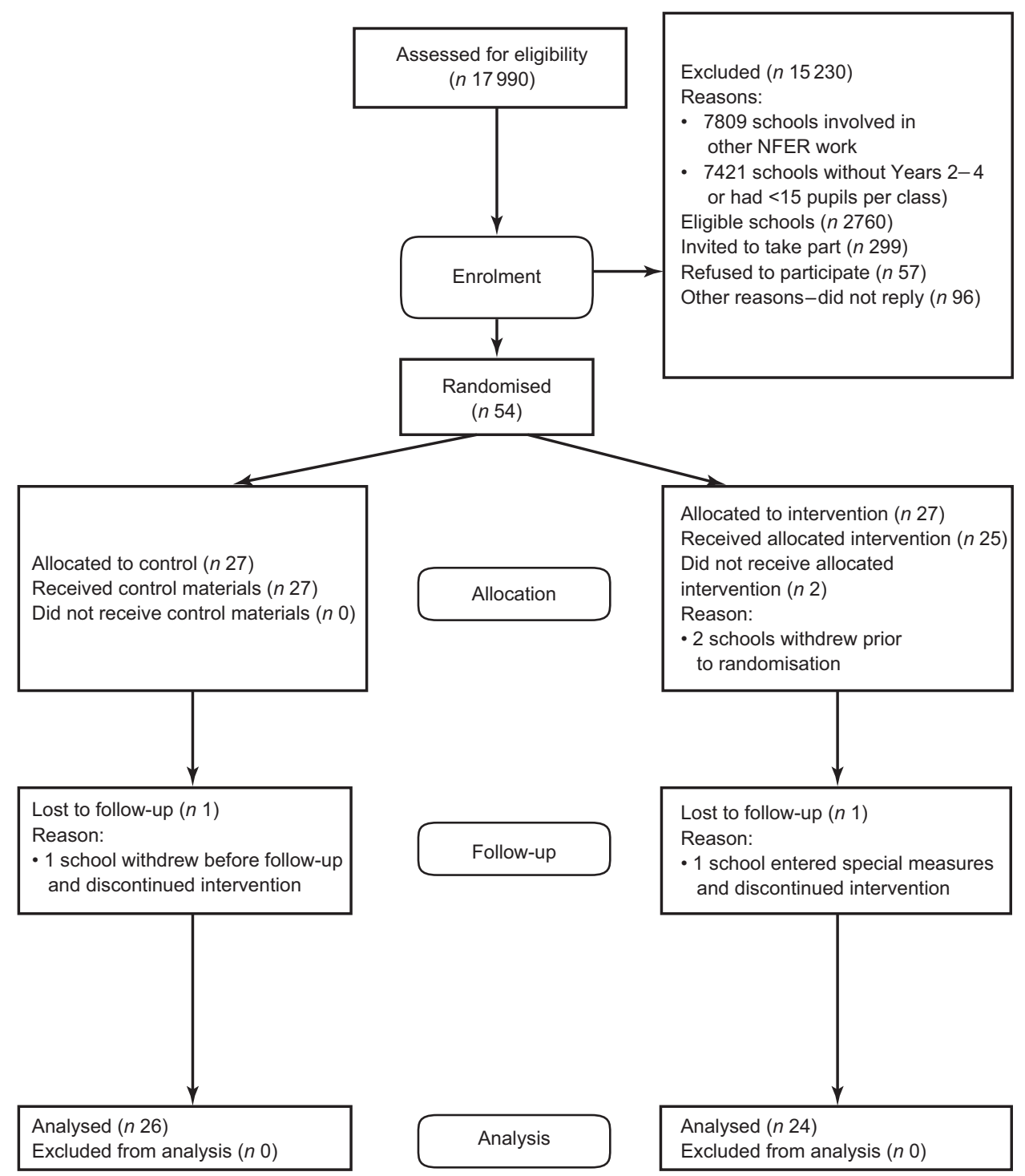

Fig. 1 Flow diagram of schools entering and completing the trial (NFER, National Foundation of Educational Research)

Fruit and vegetable consumption dropped at home and at school between baseline and follow-up for both groups. In the control group, median daily fruit and vegetable intake fell from $184 \mathrm{~g}$ to $124 \mathrm{~g}$ at home and from $193 \mathrm{~g}$ to $91 \mathrm{~g}$ at school. In the intervention group, median daily fruit and vegetable intake fell from $190 \mathrm{~g}$ to $142 \mathrm{~g}$ at home and from $189 \mathrm{~g}$ to $90 \mathrm{~g}$ at school. This drop in school fruit and vegetable intake was most likely due to children not receiving free school fruit or vegetables and also to a reduction in intake at lunch time and break time.

All twenty-four schools which completed the intervention also completed the process measures questionnaires and 261 of the 311 children who completed the trial also completed the process measures evaluation. Implementation of the intervention was low overall, with $21 \%$ of school items and $56 \%$ of home items being used. Four schools implemented the additional materials to set up cooking and gardening clubs. Further details of the process evaluation are presented elsewhere ${ }^{(30)}$.

\section{Discussion}

Project Tomato is the first large, multi-component clusterrandomised controlled trial designed to improve fruit and vegetable intake involving primary schools across England. The intervention was designed to prevent the fall in consumption of fruit and vegetables in Year 3 children, aged 8-9 years, when they are no longer eligible for free school fruit.

Despite an intensive programme of activities, the intervention, as delivered, failed to have an impact on children's fruit and vegetable intake post SFVS. The decreased intake of fruit and vegetables in these children 


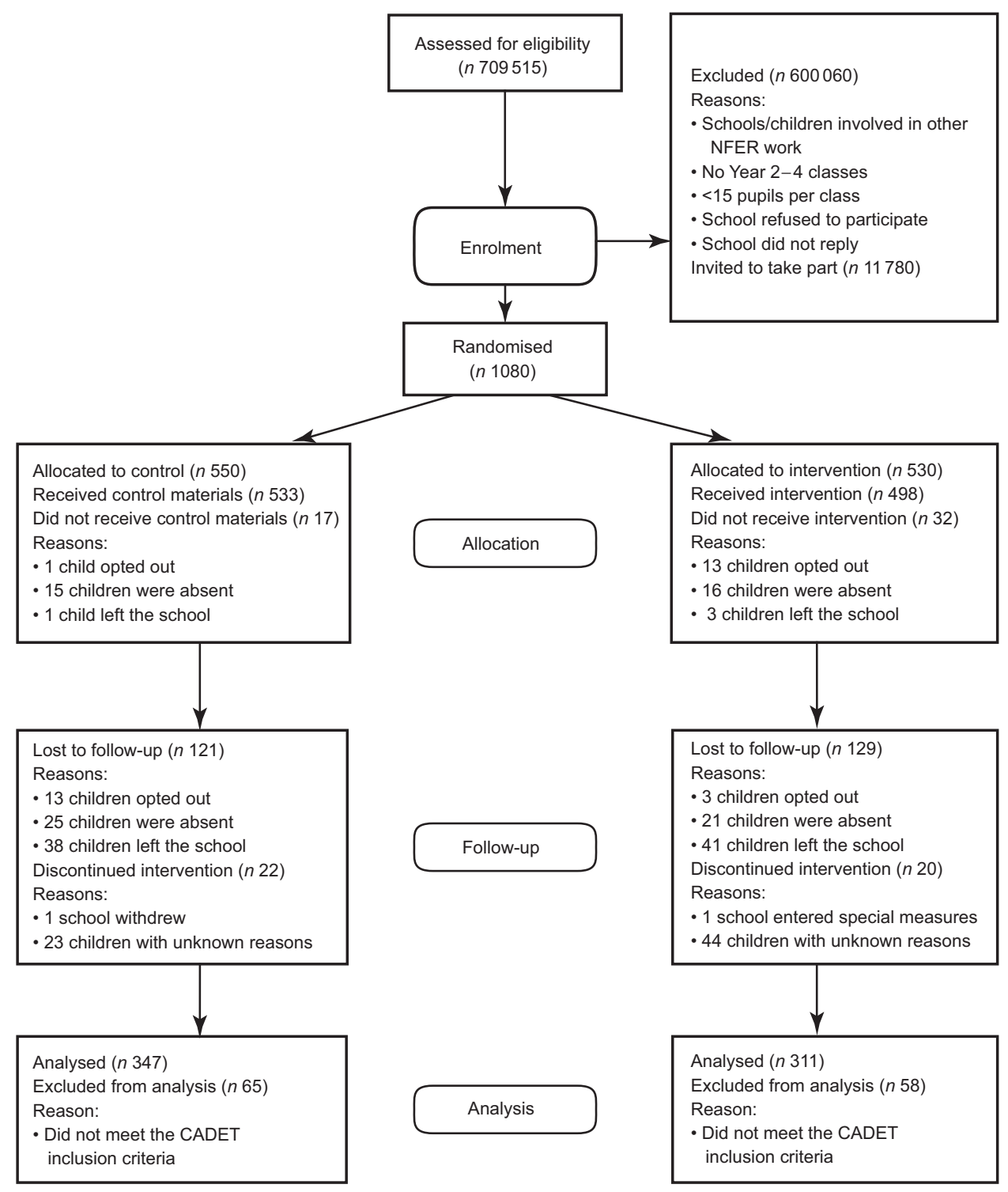

Fig. 2 Flow diagram of pupils entering and completing the trial (NFER, National Foundation of Educational Research; CADET, Child and Diet Evaluation Tool)

was particularly notable during the school day where it dropped by half. At baseline, children were receiving free school fruit and were eating more fruit than vegetables at school. When eligibility for free fruit ends, it coincides with a drop in fruit and vegetable intake. This is particularly marked at school and was not offset by the intervention. The availability of fruit during the school day, through schemes such as the SFVS, may be a key determinant of fruit intake in children. It appears difficult to make up for this loss of fruit provided either at school or home.

One reason for the lack of an intervention effect may be due to incomplete implementation. Process measure questionnaires were taken throughout the intervention from teachers, parents and children. The questionnaires measured implementation and appreciation of the intervention materials. Implementation of the intervention was low, with teachers implementing only $21 \%$ of intervention materials even though they reported that they liked the materials and activities that had been provided. Children implemented $56 \%$ of activities provided in the take-home activity kits. Parents implemented 35\% of the activities related to the intervention. Both child and parent appreciation of the intervention items was high ${ }^{(30)}$. The intervention was designed to be pragmatic, not relying on external agencies to deliver the activities; however, it appears that despite commitment from the schools and appreciation of the materials there was limited implementation.

The intervention was based on psychological constructs shown to promote behaviour change. Research in the field of health psychology suggests that the process of 
Table 1 Comparison at baseline of daily food and nutrient intakes, pupil and school characteristics, for the 658 children with complete data at baseline and follow-up; Project Tomato

\begin{tabular}{|c|c|c|c|c|}
\hline \multirow[b]{2}{*}{ Food } & \multicolumn{2}{|c|}{ Control (n 347) } & \multicolumn{2}{|c|}{ Intervention ( $n$ 311) } \\
\hline & Mean or median & $95 \% \mathrm{Cl}$ or IQR & Mean or median & $95 \% \mathrm{Cl}$ or IQR \\
\hline Fruit $(\mathrm{g})$ & 195 & 177,214 & 202 & 185,218 \\
\hline Vegetables (g) & 110 & 95,124 & 108 & 94,122 \\
\hline Fruit \& vegetables (g) & 305 & 286,324 & 309 & 287,332 \\
\hline Fruit \& vegetables $(\mathrm{g})^{*}$ & 300 & 195, 398 & 288 & 198,387 \\
\hline Energy $(\mathrm{kJ})$ & 6729 & 6496,6962 & 6634 & 6385,6883 \\
\hline Energy (kcal) & 1598 & 1543,1653 & 1575 & 1516,1634 \\
\hline Total fat $(\mathrm{g})$ & $57 \cdot 3$ & $54 \cdot 7,59 \cdot 9$ & $57 \cdot 1$ & $54 \cdot 3,59 \cdot 8$ \\
\hline Saturated fat (g) & $20 \cdot 3$ & $19 \cdot 3,21 \cdot 3$ & $20 \cdot 3$ & $19 \cdot 2,21 \cdot 3$ \\
\hline Total carbohydrate $(\mathrm{g})$ & $230 \cdot 4$ & $222 \cdot 5,238 \cdot 3$ & $225 \cdot 6$ & $217 \cdot 1,234 \cdot 1$ \\
\hline Total sugar (g) & $124 \cdot 3$ & $118 \cdot 9,129 \cdot 7$ & $119 \cdot 4$ & $113 \cdot 6,125 \cdot 2$ \\
\hline $\operatorname{NSP}(g)$ & $11 \cdot 7$ & $11 \cdot 2,12 \cdot 2$ & $12 \cdot 3$ & $11 \cdot 7,12 \cdot 8$ \\
\hline $\mathrm{Na}(\mathrm{mg})$ & 2051 & 1961, 2141 & 2098 & 2002, 2194 \\
\hline Folate $(\mu \mathrm{g})$ & $191 \cdot 6$ & $183 \cdot 0,200 \cdot 2$ & $191 \cdot 8$ & $182 \cdot 6,201 \cdot 0$ \\
\hline $\mathrm{Fe}(\mathrm{mg})$ & $9 \cdot 2$ & $8 \cdot 9,9 \cdot 6$ & $9 \cdot 3$ & $8 \cdot 9,9 \cdot 6$ \\
\hline $\mathrm{Zn}(\mathrm{mg})$ & $6 \cdot \overline{2}$ & $6 \cdot 0,6 \cdot 4$ & $6 \cdot 1$ & $5 \cdot 8,6 \cdot 3$ \\
\hline Carotenet $(\mu \mathrm{g})$ & 1552 & 1252,1923 & 1464 & 1165,1840 \\
\hline Vitamin C+ (mg) & $90 \cdot 5$ & $83 \cdot 0,98 \cdot 3$ & $90 \cdot 2$ & $82 \cdot 2,98 \cdot 5$ \\
\hline \multicolumn{5}{|l|}{ Pupil } \\
\hline Age (years) & $7 \cdot 0$ & N/A & $7 \cdot 0$ & N/A \\
\hline Sex (\% male) & $48 \cdot 1$ & $42 \cdot 6,52 \cdot 5$ & $51 \cdot 4$ & $45,57 \cdot 4$ \\
\hline Ethnicity (\% non-white) & $21 \cdot 7$ & $14 \cdot 2,33 \cdot 2$ & $14 \cdot 4$ & $8 \cdot 3,23 \cdot 1$ \\
\hline Height $(\mathrm{cm})$ & $122 \cdot 9$ & $122 \cdot 3,123 \cdot 5$ & $122 \cdot 7$ & $122 \cdot 1,123 \cdot 3$ \\
\hline Weight (kg) & $25 \cdot 1$ & $24 \cdot 6,25 \cdot 5$ & $24 \cdot 7$ & $24 \cdot 2,25 \cdot 1$ \\
\hline $\operatorname{BMI}\left(\mathrm{kg} / \mathrm{m}^{2}\right)$ & $16 \cdot 5$ & $16 \cdot 3,16 \cdot 7$ & $16 \cdot 3$ & $16 \cdot 1,16 \cdot 5$ \\
\hline Standardised BMI & 0.4 & $0.3,0.5$ & 0.3 & $0.2,0.4$ \\
\hline IMD score* & $17 \cdot 6$ & $8 \cdot 7,30 \cdot 3$ & $15 \cdot 4$ & $8 \cdot 4,25 \cdot 9$ \\
\hline \multicolumn{5}{|l|}{ School } \\
\hline$\%$ FSME (median)* & 12 & 4,27 & 9 & 3,15 \\
\hline$\%$ White British* & $92 \cdot 1$ & $70 \cdot 8,96 \cdot 6$ & $93 \cdot 5$ & $86 \cdot 8,97 \cdot 1$ \\
\hline
\end{tabular}

IQR, interquartile range; IMD, Index of Multiple Deprivation; FSME, free school meal eligibility; N/A, not applicable.

${ }^{*}$ Median and IQR (single-level model).

tNatural log.

Table 2 Follow-up daily food and nutrient intakes of the 658 children with trial data analysed, and intervention effects adjusted for age, gender and baseline results; Project Tomato

\begin{tabular}{|c|c|c|c|c|c|c|c|}
\hline \multirow[b]{2}{*}{ Food } & \multicolumn{2}{|c|}{ Control (n 347) } & \multicolumn{2}{|c|}{ Intervention (n 311) } & \multicolumn{2}{|c|}{ Intervention effect } & \multirow[b]{2}{*}{$P$ value } \\
\hline & Mean or median & $95 \% \mathrm{Cl}$ or IQR & Mean or median & $95 \% \mathrm{Cl}$ or IQR & Mean & $95 \% \mathrm{Cl}$ & \\
\hline Fruit (g) & 134 & 118,149 & 133 & 119,148 & 0 & $-20,20$ & $1 \cdot 0$ \\
\hline Fruit (portions) & $1 \cdot 7$ & $1 \cdot 5,1 \cdot 9$ & $1 \cdot 7$ & $1 \cdot 5,1.9$ & $0 \cdot 0$ & $-0 \cdot 3,0.3$ & $1 \cdot 0$ \\
\hline Vegetables (g) & 119 & 107,132 & 122 & 109,135 & 2 & $-15,19$ & $0 \cdot 8$ \\
\hline Vegetables (portions) & 1.5 & $1 \cdot 3,1 \cdot 7$ & $1 \cdot 5$ & $1 \cdot 3,1 \cdot 7$ & $0 \cdot 0$ & $-0 \cdot 2,0 \cdot 3$ & $0 \cdot 8$ \\
\hline Fruit \& vegetables $(\mathrm{g})$ & 253 & 234,273 & 255 & 237,273 & 2 & $-23,26$ & $0 \cdot 9$ \\
\hline Fruit \& vegetables (portions) & $3 \cdot 2$ & $2 \cdot 9,3 \cdot 4$ & $3 \cdot 2$ & $2 \cdot 9,3 \cdot 4$ & $0 \cdot 0$ & $-0.3,0.3$ & 0.9 \\
\hline Fruit \& vegetables $(g)^{\star}$ & 228 & 135,335 & 238 & 144,343 & 10 & $\mathrm{~N} / \mathrm{A}$ & $\mathrm{N} / \mathrm{A}$ \\
\hline Energy $(\mathrm{kJ})$ & 7103 & 6827,7379 & 7239 & 6958,7520 & 136 & $-194,467$ & 0.42 \\
\hline Energy (kcal) & 1687 & 1621,1753 & 1719 & 1652,1786 & 32 & $-46,111$ & 0.42 \\
\hline Total fat $(\mathrm{g})$ & 63.3 & $60 \cdot 1,66 \cdot 4$ & 64.5 & $61 \cdot 2,67 \cdot 7$ & $1 \cdot 2$ & $-2 \cdot 8,5 \cdot 1$ & 0.56 \\
\hline Saturated fat (g) & $22 \cdot 4$ & $21 \cdot 2,23 \cdot 6$ & $22 \cdot 4$ & $21 \cdot 1,23 \cdot 6$ & $0 \cdot 0$ & $-1.5,1.5$ & $1 \cdot 00$ \\
\hline Total carbohydrate $(\mathrm{g})$ & $235 \cdot 5$ & $226 \cdot 8,244 \cdot 2$ & $237 \cdot 4$ & $228 \cdot 6,246 \cdot 2$ & $1 \cdot 9$ & $-8 \cdot 2,12 \cdot 0$ & $0 \cdot 72$ \\
\hline Total sugar $(\mathrm{g})$ & $110 \cdot 4$ & $104 \cdot 8,116$ & $111 \cdot 5$ & $105 \cdot 8,117 \cdot 2$ & $1 \cdot 1$ & $-5 \cdot 5,7 \cdot 6$ & $0 \cdot 75$ \\
\hline NSP $(g)$ & $12 \cdot 3$ & $11 \cdot 6,13 \cdot 0$ & $12 \cdot 4$ & $11 \cdot 7,13 \cdot 1$ & $0 \cdot 1$ & $-0.7,0.9$ & 0.79 \\
\hline $\mathrm{Na}(\mathrm{mg})$ & 2334 & 2207, 2461 & 2460 & 2329, 2591 & 126 & $-36,287$ & $0 \cdot 13$ \\
\hline Folate $(\mu \mathrm{g})$ & $200 \cdot 5$ & $190 \cdot 5,210 \cdot 5$ & $205 \cdot 3$ & $195,215 \cdot 6$ & $4 \cdot 8$ & $-7 \cdot 3,17 \cdot 0$ & 0.44 \\
\hline $\mathrm{Fe}(\mathrm{mg})$ & $10 \cdot 3$ & $9 \cdot 7,10 \cdot 9$ & $10 \cdot 6$ & $9 \cdot 9,11 \cdot 2$ & $0 \cdot 3$ & $-0 \cdot 4,1 \cdot 0$ & 0.44 \\
\hline $\mathrm{Zn}(\mathrm{mg})$ & $6 \cdot 9$ & $6 \cdot 4,7 \cdot 3$ & $7 \cdot 3$ & $6 \cdot 8,7 \cdot 8$ & 0.4 & $-0 \cdot 2,1 \cdot 0$ & $0 \cdot 16$ \\
\hline Carotenet $(\mu \mathrm{g})$ & 1397 & 1169,1669 & 1474 & 1227,1772 & 78 & $-221,453$ & 0.64 \\
\hline Vitamin C+ (mg) & $69 \cdot 4$ & $63 \cdot 5,75 \cdot 9$ & $67 \cdot 7$ & $61 \cdot 8,74 \cdot 2$ & $-1 \cdot 7$ & $-8 \cdot 7,6 \cdot 0$ & 0.65 \\
\hline
\end{tabular}

IQR, interquartile range; N/A, not applicable.

*Median and IQR (single-level model).

+Natural log. 
initiating health behaviour, such as eating more fruit, may be different from maintaining the behaviour. Each type of behaviour may need a separate and distinctive intervention strategy to support it ${ }^{(31)}$. The intervention was designed to address this hypothesis by mapping key psychological constructs involved with maintenance behaviour to intervention activities.

The intervention Project Tomato involved components aimed at teachers, parents and children over a period of 10 months. It is important to note this intervention was designed to be delivered by school staff and no additional personnel were deployed. Project Tomato was also designed to be sustainable and to enable the schools to continue its delivery beyond the evaluation stage. Multicomponent interventions in this age group have been reported from the USA and shown improvements in fruit and vegetable intake of a third of a portion or more per day. A recent pooled analysis of seven studies in the USA showed an increase of 0.45 portions of fruit and vegetables consumed daily post intervention ${ }^{(32)}$. However, not all of these studies were randomised controlled trials. The studies included in the analysis were more intensive, of longer duration and included additional personnel to deliver the interventions ${ }^{(23,33,34)}$. An Icelandic study showed a $46 \%$ increase in fruit and vegetable intake in primary-school children following a school-based intervention. That study was, however, characterised by low intake of fruit and vegetables at baseline together with baseline imbalance between the intervention and control groups $^{(35)}$. One recent intervention in the UK had some success in increasing fruit and vegetables in packed lunches at schools ${ }^{(36)}$.

The age-related decline in fruit and vegetables observed in the present study is a cause for concern, particularly as the intervention was designed to attenuate this. The School Meal Standards and the restriction on advertising of food high in fat, salt and sugar to children, which were introduced after this intervention, may help to increase children's intake of fruit and vegetables ${ }^{(37,38)}$. The introduction of food-based standards for school meals in 2006 has moderately improved the nutrient content of school meals, slightly widening the nutritional gap between children consuming school meals compared with packed lunches ${ }^{(39)}$. However, packed lunches fall behind with only 19\% of packed lunches containing vegetables and $54 \%$ containing fruit for children in this age group ${ }^{(40)}$.

Powerful socio-cultural influences drive children's eating behaviour towards a more processed diet that is low in fruit and vegetables, with adolescents consuming less fruit and vegetables than younger children, particularly boys ${ }^{(10)}$. This may be hard to offset without the continued availability of free fruit during the school day. The combined fruit and vegetable intake of about $300 \mathrm{~g} / \mathrm{d}$ in the present study appears relatively high in comparison to other UK data. Findings of the National Diet and
Nutrition Survey (NDNS) found the median intake of fruit for children aged $4-10$ years was $88 \mathrm{~g} / \mathrm{d}$ and intake of cooked and raw vegetables including salad was $74 \mathrm{~g} / \mathrm{d}^{(9,10)}$, for a daily total of $162 \mathrm{~g}$ of fruit and vegetables combined. The fall in fruit intake at school in Year 3 shown in the present study may provide some evidence to support the continuation of the SFVS throughout primary school. However, more work is needed to confirm this. Some other studies have reported similar small or no improvements in fruit and vegetable intake following an intervention ${ }^{(41,42)}$ although others have been successful ${ }^{(43,44)}$.

Strengths of the present study include the strong study design, the random sampling to include all primary schools in England, and the multilevel analysis using MLwiN which took into account the clustering of children within schools. A validated dietary assessment tool was used.

There were some limitations to the study. Four schools $(\sim 120$ pupils) were lost following randomisation. Reasons for school withdrawal included the school entering special measures or undergoing an inspection. This could have led to biased results if the schools that withdrew were different from schools that remained in the trial. In addition, the children in the intervention and control groups could have been unmatched in terms of social deprivation. Although attempts were made to match schools, measures of deprivation at the individual level were not included in the model. Parents were asked for their postcode to determine an IMD (Index of Multiple Deprivation) score for each child, but a large number of families did not provide this data. Therefore including IMD in the analysis would have greatly reduced the number of children included in the final model, leading to bias if there were inherent differences between families who provided this information and those who did not.

The dietary assessment tool could also be a limitation. The portion size of some of the different fruits and vegetables may have been overestimated using this method. Accurately assessing diet remains a difficult problem and the issue with $24 \mathrm{~h}$ recalls such as CADET is that participants may overestimate intake compared with weighed diaries, where participants are more likely to underestimate consumption. Although efforts were made to exclude children who used the assessment tool as an FFQ by ticking all the fruits and vegetables that they ever ate, it is possible that some pupils were included, contributing to an overestimation of fruit and vegetable consumption. The estimated daily amounts in the present study are higher than in the NDNS where weighed diaries were used, which may be due to overestimation of the CADET tool or underestimation of NDNS data. Moreover, the diary was only completed for $1 \mathrm{~d}$, and fruit and vegetable consumption could vary considerably from day to day for each child. These issues are unlikely to have had an impact on the results of the trial as fruit and vegetable consumption would have been overestimated in both groups to the same degree. 


\section{Conclusions}

The present large, cluster-randomised controlled trial provided a unique opportunity to explore whether a multicomponent school-based intervention could increase children's consumption of fruit and vegetables. The results showed that the intervention as delivered had no positive effect on children's intake of these foods. Rather there was a marked decline following the end of the SFVS, particularly during the school day. However, the implementation of the intervention by teachers, pupils and parents was low. This raises important issues regarding how long national interventions such as the SFVS should be maintained in schools; what the effects of withdrawing an intervention may be; and the challenges facing the implementation of dietary interventions during the busy school day. These findings suggest that further work is required to improve the delivery and implementation of school-based interventions to improve fruit and vegetable consumption and to prevent the age-related decline in fruit and vegetable intake.

\section{Acknowledgements}

Sources of funding: This work was supported by the National Prevention Research Initiative of the UK Medical Research Council. Conflicts of interest: All authors declare that they have no conflicts of interest. Authors' contributions: J.K.R. was responsible for managing the project, designing the intervention and writing the first draft of the paper. C.E.L.E. was responsible for analysing the data and updating the paper. M.S.C. was responsible for day-to-day running of the project, designing the intervention and updating the paper. D.C.G. was responsible for the overall statistical design of the trial and overseeing the analysis of the programme. J.D.T. was responsible for the database. J.E.C. was responsible for updating the paper and overall management of the project. Acknowledgements: The authors thank the children, parents and schools for their involvement in the study.

\section{References}

1. World Health Organization (2004) Global Strategy on Diet, Physical Activity and Health. Geneva: WHO.

2. World Cancer Research Fund \& American Institute for Cancer Research (2007) Food, Nutrition and Physical Activity and the Prevention of Cancer: A Global Perpsective. Washington, DC: WCRF/AICR.

3. Block G, Patterson B \& Sumar A (1992) Fruit, vegetables, and cancer prevention: a review of the epidemiological evidence. Nutr Cancer 18, 1-29.

4. Maynard M, Gunnell D, Emmett P et al. (2003) Fruit and vegetables and antioxidants in childhood and risk of adult cancer: the Boyd Orr Cohort. I Epidemiol Community Health 57, 218-225.

5. Fisher J, Mitchell D, Smiciklas-Wright $\mathrm{H}$ et al. (2002) Parental influences on young girls' fruit and vegetable, micronutrient, and fat intakes. J Am Diet Assoc 102, 58-64.
6. Go for 2 \& 5 website (no date) http://www.gofor2and5. com.au/ (accessed December 2012).

7. Eriksen K, Haraldsdottir J, Pederson R et al. (2003) Effect of a fruit and vegetable subscription in Danish schools. Public Health Nutr 6, 57-63.

8. Appleton KM, Rogers PJ \& Blundell JE (2004) Effects of a sweet and a nonsweet lunch on short-term appetite: differences in female high and low consumers of sweet/ low-energy beverages. J Hum Nutr Diet 17, 425-434.

9. Ransley J, Greenwood D, Cade J et al. (2007) Does the school fruit and vegetable scheme improve children's diet? A non-randomised controlled trial. J Epidemiol Community Health 61, 699-703.

10. Gregory J, Lowe S, Bates C et al. (2001) National Diet and Nutrition Survey: Young People Aged 4 to 18 Years. London: The Stationery Office.

11. Magarey A, Daniels LA \& Smith A (2001) Fruit and vegetable intakes of Australians aged 2-18 years: an evaluation of the 1995 National Nutrition Survey data. Aust N Z J Public Health 25, 155-161.

12. Krebs-Smith SM, Cook A, Subar AF et al. (1996) Fruit and vegetable intakes of children and adolescents in the United States. Arch Pediatr Adolesc Med 150, 81-86.

13. Department of Health (2003) 5 A Day Introduction. London: Department of Health.

14. Department of Health (2002) Information for Schools: School Fruit and Vegetable Scheme. London: Department for Health.

15. Kitchen MS, Ransley JK, Greenwood DC et al. (2009) Study protocol: a cluster randomised controlled trial of a school based fruit and vegetable intervention - Project Tomato. BMC Health Serv Res 9, 101.

16. Wells L, Nelson M, Wells L et al. (2005) The National School Fruit Scheme produces short-term but not longer-term increases in fruit consumption in primary school children. Br J Nutr 93, 537-542.

17. Fogarty AW, Antoniak M, Venn AJ et al. (2007) Does participation in a population-based dietary intervention scheme have a lasting impact on fruit intake in young children? Int J Epidemiol 36, 1080-1085.

18. Baranowski T, Davis M, Resnicow K et al. (2000) Gimme 5 fruit, juice, and vegetables for fun and health: outcome evaluation. Health Educ Behav 27, 96-111.

19. Gortmaker SL, Cheung LW, Peterson KE et al. (1999) Impact of a school-based interdisciplinary intervention on diet and physical activity among urban primary school children: eat well and keep moving. Arch Pediatr Adolesc Med 153, 975-983.

20. Gortmaker SL, Peterson K, Wiecha J et al. (1999) Reducing obesity via a school-based interdisciplinary intervention among youth: Planet Health. Arch Pediatr Adolesc Med 153, 409-418.

21. Bere E, Veierod MB, Bjelland M et al. (2006) Outcome and process evaluation of a Norwegian school-randomized fruit and vegetable intervention: Fruits and Vegetables Make the Marks (FVMM). Health Educ Res 21, 258-267.

22. Taylor RW, McAuley KA, Barbezat W et al. (2007) APPLE project: 2-y findings of a community-based obesity prevention program in primary school age children. $A m J$ Clin Nutr 86, 735-742.

23. Reynolds KD, Franklin FA, Binkley D et al. (2000) Increasing the fruit and vegetable consumption of fourth-graders: results from the high 5 project. Prev Med 30, 309-319.

24. Anderson A, Porteous L, Foster E et al. (2005) The impact of a school-based nutrition education intervention on dietary intake and cognitive and attitudinal variables relating to fruits and vegetables. Public Health Nutr 8, 650-656.

25. Sahota P, Rudolf MC, Dixey R et al. (2001) Randomised controlled trial of primary school based intervention to reduce risk factors for obesity. BMJ 323, 1029-1032. 
26. Knai C, Pomerleau J, Lock K et al. (2006) Getting children to eat more fruit and vegetables: a systematic review. Prev Med 42, 85-95.

27. Conner M \& Sparks P (2005) The theory of planned behaviour and health behaviour. In Predicting Health Behaviour, pp. 170-222 [M Conner and P Norman, editors]. Milton Keynes: Open University Press.

28. Cade JE, Frear L, Greenwood DC et al. (2006) Assessment of diet in young children with an emphasis on fruit and vegetable intake: using CADET - Child and Diet Evaluation Tool. Public Health Nutr 9, 501-508.

29. Rasbash J, Steele F, Browne WJ et al. (2004) A User's Guide to MLwiN, Version 2.0. London: Institute of Education.

30. Christian MS, Evans CE, Ransley JK et al. (2012) Process evaluation of a cluster randomised controlled trial of a school-based fruit and vegetable intervention: Project Tomato. Public Health Nutr 15, 459-465.

31. Armitage C \& Conner M (2000) Social cognition models and health behaviour: a structured review. Psychol Health 15, 173-189.

32. Howerton MW, Bell BS, Dodd KW et al. (2007) Schoolbased nutrition programs produced a moderate increase in fruit and vegetable consumption: meta and pooling analyses from 7 studies. J Nutr Educ Behav 39, 186-196.

33. Perry CL, Bishop DB, Taylor G et al. (1998) Changing fruit and vegetable consumption among children: the 5-a-Day Power Plus program in St. Paul, Minnesota. Am J Public Health 88, 603-609.

34. Cullen KW, Watson K, Baranowski T et al. (2005) Squire's quest: intervention changes occurred at lunch and snack meals. Appetite 45, 148-151.

35. Kristjansdottir A, Johannsson E \& Thorsdottir I (2010) Effects of a school-based intervention on adherence of 7-9-year-olds to food-based dietary guildelines and intake of nutrients. Public Health Nutr 13, 1151-1161.
36. Evans CE, Greenwood DC, Thomas JD et al. (2010) SMART lunch box intervention to improve the food and nutrient content of children's packed lunches: UK wide cluster randomised controlled trial. J Epidemiol Community Health 64, 970-976.

37. Children's Food Trust (2012) The standards. http://www. childrensfoodtrust.org.uk/the-standards (accessed December 2012).

38. Office of Communications (2008) Update on impact of restrictions on food and drink advertising to children. http://stakeholders.ofcom.org.uk/market-data-research/ other/tv-research/update/ (accessed December 2012).

39. Evans CE, Cleghorn CL, Greenwood DC et al. (2010) A comparison of British school meals and packed lunches from 1990 to 2007: meta-analysis by lunch type. Br J Nutr 104, 474-487.

40. Evans CE, Greenwood DC, Thomas JD et al. (2010) A crosssectional survey of children's packed lunches in the UK: food- and nutrient-based results. J Epidemiol Community Health 64, 977-983.

41. Bere E, Veierod MB \& Klepp K-I (2005) The Norwegian School Fruit Programme: evaluating paid vs. no-cost subscriptions. Prev Med 41, 463-470.

42. Te Velde SJ, Brug J, Wind $M$ et al. (2008) Effects of a comprehensive fruit and vegetable promoting school based intervention in three European countries: the Pro Children Study. Br J Nutr 99, 893-903.

43. Ciliska D, Miles E, O'Brien MA et al. (2000) Effectiveness of community-based interventions to increase fruit and vegetable consumption. J Nutr Educ Behav 32, 341-352.

44. Auld G, Romaniello C, Heimendinger J et al. (1998) Outcomes from a school-based nutrition education program using resource teachers and cross-disciplinary models. J Nutr Educ 30, 268-280. 